\title{
La "Vénus de Milo" de Leconte de Lisle. Un ejemplo de recodificación sígnica en la poesía francesa del s. XIX
}

\section{The "Vénus de Milo" of Leconte de Lisle. An example of signic recoding in French poetry of nineteenth century}

\author{
Alejandra Spagnuolo NANNI \\ Universidad Complutense de Madrid \\ alejandraspagnuolo@msn.com
}

Recibido: 12-03-2014

Aceptado: 14-05-2015

\section{Resumen}

El propósito de este artículo es reflexionar, a partir del poema "Vénus de Milo" de Leconte de Lisle, sobre el proceso de "recodificación sígnica" que esta conocida estatua experimentó en el Imaginario literario francés durante la primera mitad del s. XIX y que la convirtió rápidamente en símbolo inequívoco de la Belleza Ideal. A tal efecto, el artículo comenzará con una breve introducción en la que se examinará el papel desempeñado inicialmente por críticos, arqueólogos e historiadores del Arte para, a continuación, analizar cómo Leconte de Lisle asumió y "remodeló" esa recodificación para adaptarla a su ideario poético.

Palabras clave: Venus de Milo, Venus celeste, Leconte de Lisle, recodificación sígnica, Belleza ideal, escultura griega.

\section{Abstract}

The present article aims to give new thought, on the basis of the poem "Vénus de Milo" by Leconte de Lisle, to the process of "signic recoding" to which the aforementioned statue was subjected in the French Literary Imaginary during the first half of the 19th century, process that quickly turned it into unequivocal symbol 
of the Ideal Beauty. Pursuing this purpose, the article unfolds from a brief introduction in which will be examined the role played initially by critics, archaeologists and historians of art to, subsequently, analyze how Leconte de Lisle assumed and "remodeled" the cited recoding in order to adapt it to his poetic ideology.

Keywords: Venus de Milo, Leconte de Lisle, signic recoding, ideal Beauty, Greek sculpture.

\section{Una nueva Venus llega desde Grecia}

En febrero de 1820 (veintiséis años antes de que Leconte de Lisle publicara la primera versión de su poema "Vénus de Milo"), un campesino griego llamado Yórgos Kendrotás encontró, mientras trabajaba sus tierras en la isla de Milo, una estatua antigua de grandes proporciones. Tras un peligroso periplo en el que no faltaron ni los conflictos diplomáticos derivados de su compra-venta ni una azarosa travesía marítima en la que se vio seriamente dañada, la estatua llegó a París en $1821^{1}$ donde causó tanto asombro y admiración como lo habría hecho la propia Venus "quand, au sortir de l'onde, elle apparut pour la première fois aux regards des dieux" 2 . Ese mismo año fue donada por Luis XVIII al Museo del Louvre que había visto significativamente mermados sus fondos seis años antes por la devolución a Italia de la Venus de Medici ${ }^{3}$ y el Apolo de Belvedere ${ }^{4}$.

Durante el reinado de Napoleón, París había sustituido a Roma como epicentro de los debates sobre la escultura clásica ${ }^{5}$. Gracias a un nuevo enfoque metodológico que aunaba los análisis de los geólogos franceses y la sabiduría de los más famosos anticuarios italianos 6 , tuvo lugar a lo largo de esos años una importante re-catalogación de obras conocidas y la incorporación a las colecciones estatales de las nuevas "adquisiciones" de Napoleón.

En 1816, momento en el que el estudio de los mármoles ${ }^{7}$ se había afianzado como método de autentificación artística y el debate sobre la escultura antigua pare-

\footnotetext{
1 Coincidiendo en el tiempo con la Declaración de Independencia griega.

2 Morey 1867, La Vénus de Milo, Nancy, Ve. Raybois, 1867, p. 3

3, La Venus de Medici, una copia romana (s. I a.C.) de un original griego realizado en bronce a partir del modelo praxiteliano de la Venus de Cnido, fue devuelta a la Galleria degli Uffizi en 1815.

4 J. J. Winckelmann (teórico neoclásico del s. XVIII) consideró al Apolo Belvedere como el ejemplo perfecto de la Belleza clásica.

5 Montègre, G., «L'expertise artistique entre science et politique. Échanges et controverses autour de l'origine des marbres antiques entre Rome et Paris», en Genèses, 65 (2006/4), Paris, Belin, 2006, p. 42.

${ }^{6}$ Entre ellos el reputadísimo Ennio Quirino Visconti.

7 Determinando las canteras a las que pertenecían.
} 
cía haberse centrado en el estudio de copias romanas tardías de originales griegos perdidos, el British Museum adquirió los frisos del Partenón. Su exhibición provocó un re-descubrimiento europeo de la escultura griega que se vería reforzado a nivel continental con la llegada de otras obras "originales" como la Venus de Milo al Louvre (1821) o los mármoles del Templo de Afaia a la Gliptoteca de Munich (1830).

Estos nuevos hallazgos generaron un cambio en el modo de observar y valorar el arte clásico en su conjunto. París, como otras ciudades europeas, se vio deslumbrada por el "genio griego" y ese deslumbramiento tuvo como consecuencia una desvalorización significativa de las hasta entonces apreciadas copias romanas tal como reflejan las palabras del crítico Alexandre Vinet recogidas por René Canat

Statues antiques, mais copies ou imitations de certaines oeuvres célèbres, ces modèles accussent pour la plupart une influence romaine; l'accent, l'individualité que caractérisaient les originaux ne se retrouvent plus ici... C'est ce faux idéal, cet art abstrait et sans racines qui a accumulé contre l'antique une masse de preventions ${ }^{8}$.

A esa exaltación de la "autenticidad" se añadió una crítica feroz a las restauraciones artísticas realizadas hasta ese momento que generó, a su vez, una "mística de la fragmentación" ". Este fervor por los originales nos ha dejado abundantes testimonios no sólo relacionados con la escultura griega sino también respecto al arte en general. Théophile Gautier, por ejemplo, reflexionó en diversas ocasiones sobre el escaso valor de las copias respecto a las obras originales. En un artículo sobre pintura que escribió en 1845 para L'Artiste planteaba que la frialdad de las copias (a pesar de ser éstas más precisas y regulares que los originales) se debía a que los artistas habían trabajado más con la vista que con el pensamiento ${ }^{10}$. En lo literario, también se mostró muy crítico sobre el valor de las fuentes clásicas de las que había bebido la literatura francesa ${ }^{11}$ precisamente en un momento de crisis en el que el acercamiento a las literaturas extranjeras había comenzado a clarificar las fronteras

\footnotetext{
8 Canat, R., La Renaissance de la Grèce Antique (1820-1850), Paris, Hachette, 1911, p. 222. Mientras no se indique lo contrario, las negritas son mías.

9 A propósito de la "mutilación” de la Venus de Milo, Jules Janin escribió lo siguiente en 1839: “...la Vénus de Milo, cette merveille mutilée par le temps, si belle encore dans ce fragment qui nous reste, dégradation puissante qui, bien étudiée, doit enfanter des chefs-d'oeuvre pendant mille ans encore." Janin, J., «Salon de 1839», L’Artiste, 2e série / T. II / 22e liv. (1839), Paris, p. 301.

10 Gautier, Th., «Les origineaux et les copies», L'Artiste. Revue de Paris, 4e série / T. IV / 7e liv. (24 aout 1845), Paris, pp. 109-111.

11 'En général ce que l'on a pris jusqu'à présent pour le goût grec n'est guère que le goût latin. On a vu Euripide à travers Sénèque, rien n'est plus dissemblable. La littérature latine n'est guère formée que des centons de la littérature grecque; mais il y a entre l'une et l'autre toute la différence de l'original à la copie, du mouvement libre au geste parodié, du dessin au poncif, de la forme taillée dans le paros au surmoulage en plâtre”. En Canat 1911, op. cit. (nota 8), p. 221.
} 
entre imitación, recreación y traducción, y la dicotomía paganismo-cristianismo (que tanto afectaría a la herencia latina) se había reactivado ideológica y estéticamente en el estudio de la Antigüedad12.

En los años siguientes a la llegada de la Venus de Milo a París, las especulaciones sobre su origen y el tipo de Venus representada (derivadas todas ellas de la escasez de información y de la ausencia de atributos específicos) aumentaron considerablemente entre los arqueólogos y entre los artistas e historiadores.
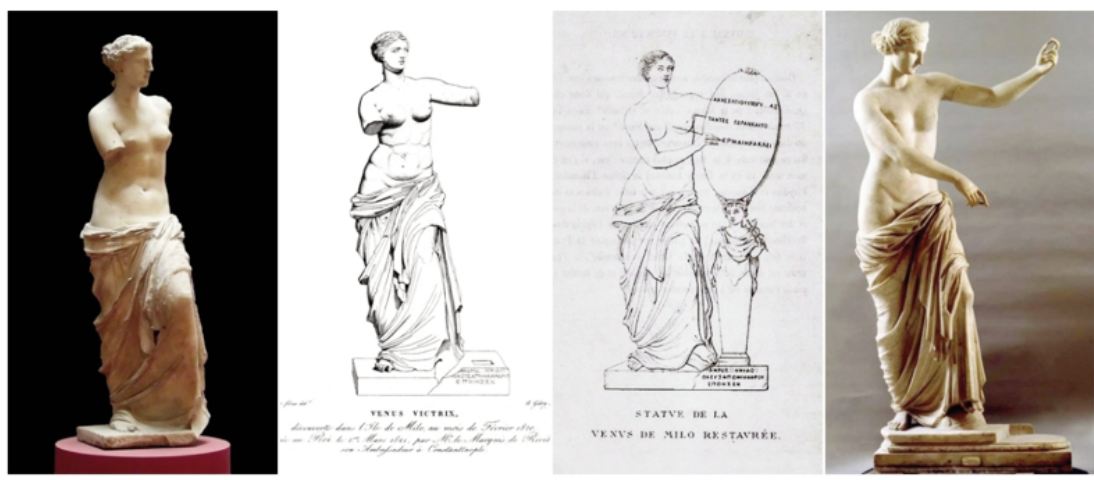

[La Venus de Milo tal como puede verse actualmente en el Museo del Louvre; un grabado realizado en 1821 por Alexandre Giboy a partir de un dibujo de Debay en el que puede apreciarse aún parte del brazo izquierdo y el plinto con la inscripción perdida; la imagen "restaurada" de la estatua tal como aparece en el relato de Prosper Moray; xy la Venus de Capua (copia romana del siglo II d.C. de un bronce griego del s. IV a.C., considerada por algunos la obra inspiradora de la Venus del Louvre) que se cree perteneció a un conjunto escultórico en el que

Venus aparecía entregándole a Marte sus armas]

En menos de dos décadas, ese complejo flujo especulativo, que se alimentó a la par de reflexiones estético-filosóficas y de intereses socio-políticos, se materializó en una "recodificación sígnica" que, como veremos a lo largo del análisis del poema de Leconte de Lisle, convirtió a la Venus de Milo en símbolo de esa belleza imperecedera que tanta relevancia tendría años más tarde para la poesía parnasiana.

\section{La "Vénus de Milo" de Leconte de Lisle}

En marzo de 1846, Leconte de Lisle publicó en La Phalange13 la primera de las cinco versiones ${ }^{14}$ de su poema "Vénus de Milo". Todavía habrían de pasar seis años

\footnotetext{
12 García Jurado, F., «Construcción moderna de la Historia de la Literatura latino-cristiana: la actualización del conflicto entre cristianos y paganos», en De cara al Más Allá: conflicto, convivencia y asimilación de modelos paganos en el cristianismo antiguo, Zaragoza, Libros Pórtico, 2010, pp. 139-160. 13 Publicación fourierista con la que colaboraba en ese momento.

14 Las cuatro restantes (de 1852, 1858, 1874 y 1886 respectivamente) corresponden a las sucesivas reediciones de Poèmes Antiques en las que "Vénus de Milo" aparece ya como uno de sus "poemas griegos".
} 
antes de la publicación de Poèmes antiques en cuyo conocido Préface anunciaría el nacimiento de una nueva escuela poética15. A pesar de eso, su "Vénus de Milo", al igual que otros poemas suyos de esta época, refleja ya una más que notable fascinación por la cultura clásica que, contrariamente a lo que se tiende a pensar, no fue exclusiva de la poesía parnasiana aunque la influencia de Leconte de Lisle en gran número de poetas anti-románticos fuera decisiva a la hora de convertir ese amor por la Antigüedad en una de las señas de identidad del Parnaso. La búsqueda de una nueva conexión con la Grecia clásica 16 fue, por encima de todo, el indicador de un deseo de cambio no sólo en poetas y artistas sino también en una parte del público cansada ya de la "laxitud" estética del romanticismo17.

El poema ${ }^{18}$, cuyo tema es la exaltación de la Belleza ideal, está concebido como una oda de quince cuartetos de alejandrinos ${ }^{19}$ divididos estructuralmente en dos partes: invocación y petición.

Leconte de Lisle comienza su poema dirigiéndose a la estatua que, en su imaginario personal, es a la vez presencia viva de la Belleza y representación ideal de la misma. Para "ilustrar" esa complejidad, emplea un motivo de tipo funcional basado en la disposición léxica y la estructuración métrica de las dos primeras estrofas 20 . En este motivo, en el que hay una gran concentración semántica, los versos extremos hablan de la extraordinaria materialidad de la estatua; los interiores, de la diosa

\footnotetext{
15 Leconte de Lisle, Ch. M., Poèmes antiques, Paris, Éditions Gallimard, 1994, p. 312.

16 Gracias, paradójicamente, a los autores románticos que habían resuelto el conflicto con la Antigüedad adoptando la literatura griega como una literatura extranjera y no como parte de esa herencia clásica de naturaleza prescriptiva en la que había primado "la tyranie des règles" y en la que "l'imitation était devenue purement formelle". Ducros, J., Le retour de la poésie française, à l'antiquité grecque au milieu du XIXe siècle. Leconte de Lisle et les "Poèmes Antiques". Notes sur les sources de Leconte de Lisle, Paris, Librairie Armand Colin, 1918, p. 14-16.

17 'Faut-il donc s'étonné, à cette heure, que le public, fatigué de lire tant d'apothéoses personnelles, d'assister à la toilette de tant de martyres, d'ouïr tant de voix de plus en plus intérieures, fasse enfin la sourde oreille et se refuse à faire preuve de patience plus longtemps? Non, certes! Le public a raison. Assez de poésie égoïste comme cela! assez de gazettes particulières arrangées en hémistiches! assez de confessions et de confidences pueriles! Il se fait temps d'être sérieux, poétes. Laissez là toutes ces inútiles divagations sur vos douleurs intimes, sur la candeur de vos femmes ou sur l'espiéguerie de vos enfants. Occupez-vous un peu de ce qui se passe hors de vous-même, sous peine de n'excité chez les autres que la pitié ou le dédain”. Chaudes-Aigues, «L'état présent de la Littérature», L'Artiste, 2e série / T. V /4e liv. (1840), p. 50.

18 Mientras no se indique lo contrario, la versión analizada será siempre la de 1846.

19 La versión definitiva será de diez estrofas. Según J. Ducros, a partir de la versión de 1852 de La Vénus de Milo disparaissent les strophes qui précisaient dans un sens fouriériste l'idéal grec. Ducros 1918, op. cit. (nota 16), p. 45.

20 Para Leconte de Lisle "les idées, en étymologie exacte [ i $\delta \varepsilon \varepsilon \alpha=$ forma, concepto] et en strict bons sens, ne peuvent être que des formes et [...] les formes son l'unique manifestation de la pensée." Leconte de Lisle, Ch. M., Articles. Préfaces. Discurs. Paris, Société d'édition "Les Belles lettres", 1971, p.147.
} 
representada y del poder que ésta posee; y los centrales, de la Idea que subyace bajo esa representación mítica

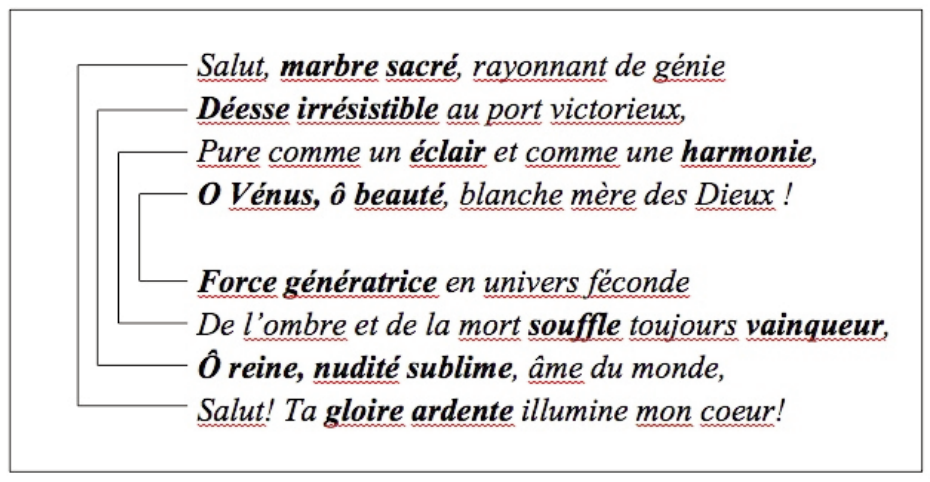

Uno de los aspectos que más contribuyeron a la conversión de esta estatua en símbolo de la Belleza Ideal fue el de su materialidad marmórea a la que el s. XIX le concedió una relevancia que excedió lo estrictamente material. Baudelaire, por ejemplo, criticó la excesiva popularidad del mármol como materia de un arte que "lo solemniza todo, incluso el movimiento aportándole a lo humano algo eterno que participa de la dureza de la materia empleada"21; otros como Hugo, Gramont, Guérin, Vigny o Gautier pensaron que "la dureté et la pureté du marbre suggèrent le mystère connexe à la beauté" 22 ; mientras para Hegel ${ }^{23}$ su blancura, pureza, brillo y buena reflexión de la luz habían contribuido en el mundo clásico no sólo a una incipiente abstracción de las formas sino también a una perfecta representación de los más altos valores 24 . Por otra parte, no debemos olvidar que, más allá del material empleado, en el pensamiento hegeliano la escultura griega representa la unión perfecta y armoniosa de lo espiritual con lo corporal gracias a "l'absence de divorce ou de combat entre la chair et l'esprit"'25. En el motivo inicial del poema de Leconte de Lisle, podemos encontrar algunos ejemplos de esa unión armoniosa, y hasta cierto punto misteriosa, en la que brillan en perfecto y eterno equilibro lo cor-

\footnotetext{
21 Baudelaire, Ch., «Escultura», Salones y otros escritos sobre arte, Madrid, Antonio Machado Libros, 2005, pp. 282-283

22 Juden, B., Traditions orphiques et tendences mystiques dans le romantisme français, Genève, Éditions Slatkine, 1984, p. 511.

${ }^{23} \mathrm{La}$ influencia filosófica de Hegel fue muy importante en los círculos académicos parisinos especialmente a partir de 1840 cuando Victor Cousin, uno de sus más fervientes defensores en la Sorbona, fue elegido "Ministre d'instruction". Ese mismo año Charles Magloire Bénard comenzó la traducción de su obra completa al francés.

${ }^{24}$ Larfouilloux, J., «La place de la sculpture dans la pensé philosophique occidentale. Remarques sur la théorie hégélienne de la sculpture», en Rue Descartes, $\mathrm{n}^{\circ} 71$ (2011), p. 59.

25 Larfouilloux (2011), op. cit. (nota 24), p.60.
} 
póreo y lo inmaterial (marbre sacré, rayonnant de génie... pure comme un éclair... blanche mère des Dieux...ta gloire ardente illumine mon coeur...).

En los versos interiores, el poeta da un paso más allá de la materia y nos presenta a la diosa (deése irresistible... âme du monde) y a su peculiar desnudez (nudité sublime). Seis años antes, en una línea muy similar a la seguida por Leconte de Lisle, George Sand 26 había asociado la desnudez de la Venus de Milo con la Belleza ideal haciendo especial hincapié en la castidad de la representación

Tous les hommes ont soif du beau; il faut que leur âme boive à cette source de vie ou qu'elle périsse [...] À ceux chez qui la beauté ne peut que se manifester que par les sens, donnez pour préservatif contre la débauche, la nudité de la Vénus de Milo. Voyez votre erreur à vous autres moralistes, qui vous détournez avec crainte de cette beauté matérielle comme d'un objet impudique et propre à troubler les sens. Si vous compreniez l'art, vous sauriez que le beau est chaste, car il est divin. L'imagination s'éloigne de la terre et remonte aux cieux en contemplant le produit d'une inspiration céleste; car ce produit, c'est l'idéal. ${ }^{27}$

En las palabras de Sand se perciben aún resonancias de la estética neoclásica que en el último tercio del s. XVIII había desvinculado la representación bella de los cuerpos de la mímesis de la realidad sensible, y que, a su vez, había tolerado el desnudo heroico femenino ${ }^{28}$ como la representación inevitable de unas pocas figuras míticas entre las que destacaba, como es lógico, Venus /Afrodita.

El cambio que observamos en la valoración del desnudo no "púdico" de la Venus de Milo en los textos de George Sand y Leconte de Lisle obedece, en mi opinión, a la fusión de dos tendencias posteriores aparentemente contrapuestas en las que "desaparece" la vergüenza por la desnudez. La primera de ellas es la del desnudo parcial femenino que se impuso tras la Revolución francesa como representación alegórica del nuevo poder 29 ("Tu marches, fière et nue, et le monde palpite, / et le monde est à toi..." vv. 35-36). La segunda, la del desnudo como representación de le féminin céleste ${ }^{30}$ que, partiendo literariamente de Goethe ${ }^{31}$, nos remitiría nuevamente a la Antigüedad y a las teorías filosóficas de Platón.

\footnotetext{
26 "George Sand occupait une place de choix parmi les auteurs de prédilection du jeune homme. Elle aussi contribua à developer sa conscience littéraire, son impérieux besoin de perfection et sa nécessité de croire en une société plus fraternelle". En Carrère, Ch., Leconte de Lisle ou la passion du beau, Paris, Fayard, 2009, p. 68.

27 Sand, G., Les sept cordes de la lyre, Paris, Bonnaire, 1840, p.119.

28 'C $C$ 'est au nu masculin qu'il revenait d'incarner les tensions entre sensualité et modèle de vertu. Le corps féminin exprimait peut-être, dans certains cas exceptionnels, un sentiment supérieur avec conviction, mais il lui était interdit, une fois denude, d'être le vecteur de l'exemplum virtutis". En Guédron, M., «Le nu héroique ou les vertus régénératrices de la beauté au XVIIIe siècle», en Champ Psychosomatique, 26 (2002), p. 31

29 Ibidem, p. 32

30 En uno de sus artículos para L'Artist de 1845 Gérard de Nerval (uno de los traductores al francés de Goethe) recuerda precisamente la famosa frase de Fausto durante su visita a la isla de Citera en
} 
La presencia divina (Déesse irresistible... âme du monde) evocada por Leconte de Lisle corresponde como puede comprobarse en el verso 27 (Ton cortège est formé d'étoiles cadencées) a la Afrodita Urania de la que hablan los contertulios de Sócrates en el El Banquete de Platón, esa force génératrice (v. 5) que transfiguraba filosóficamente la naturaleza humana gracias a la sublimación del deseo en anhelo de eternidad

...el verdadero amante asciende desde lo humano hacia lo eterno, pasando del amor por los cuerpos bellos al observado en un único cuerpo, y de éste al amor por el alma, y del amor por la belleza de las almas al amor por la belleza misma en sí y al amor por el conocimiento del verdadero bien... 32

De su Venus, Leconte de Lisle nos dice inicialmente que es pure comme un éclair et comme une harmonie (v. 3), es decir, que es a la vez fulgor revelador y comprensión racional del universo, además de soplo de vida (de l'ombre et de la mort souffle toujours vainqueur, v.6) como la misteriosa diosa a la que alude Gérard de Nerval en su artículo sobre los templos de la Afrodita Urania de Citera.

...cette Vénus si différente de celle des peintres et des poètes, qu'Orphée invoquait en ces termes: Vénérable déesse, qui aimes les ténèbres... visible et invisible... dont toutes choses émanent, car tu donnes des lois au monde entier, et tu comendes même aux Parques, ô souveraine de la nuit!33

Sin embargo, a pesar de las reminiscencias órficas que encontramos en el poema, donde realmente resplandece la Venus de Milo de Leconte de Lisle es en el plano estético-filosófico. De ahí que el poeta insista una y otra vez en distinguirla de otras Afroditas y de las representaciones plásticas asociadas a su sensualidad

Tu n'est pas Aphrodite, au bercement de l'onde (v. 9);

Tu n'est pas Kythérée, en ta pose assouplie / Parfumant de baisers l'Adonis bienheureux (vv. 13-14);

Tu n'est pas Callipyge aux formes provoquantes / La pudique Vénus, ni la molle Astarté" (vv. 17-18)

\footnotetext{
busca de los templos de Afrodita Urania descritos por Pausanias. Nerval, G., «Souvenirs de l'Archipel», L'Artiste, 4e série / T. IV / 5e liv. (1 juin 1845), pp. 70-72.

31 Según Ducros, Leconte de Lisle fue un gran admirador de Goethe gracias a las traducciones de Blaze y Nerval aparecidas a partir de 1840. Así lo atestiguan dos poemas suyos («Hélène» y «La Recherche du Dieu») también publicados en La Phalange. Ducros 1981, op. cit. (nota 16), p. 49.

32 García Gual, C., «Introducción» en Platón, El Banquete, Madrid, Alianza Editorial, 2005, p. 32.

${ }^{33}$ Nerval (1845), op. cit. (nota 30), p. 72.
} 
La Venus de Leconte de Lisle simboliza la Belleza absoluta (Tu contiens leurs beautés dans ta beauté royale, v. 23) que al hallarse más allá del tiempo y del espacio no participa de lo dolorosamente humano (Et tu n'a point connu le trouble et la douleur, v. 24).

Tout s'altère, tout succombe, tout meurt, excepté elle, qui, même ensevelie, reste belle d'une beauté incorruptible, comme les mathématiques restent vrais d'unes vérité éternellement immutable, qui peut être enfouie ou voilée, mais non vieillir ni changer. Le spectateur mobile disparaît; l'art, fondé sur l'éternel, subsiste. 34

Con esa "distancia", que en el poema se concreta en tranquilidad ("Calme comme la mer en sa serenité"35) e imperturbabilidad (bonheur impassible), acaba la invocación.

En la segunda parte del poema, Leconte de Lisle comienza su petición con tres tópicos literarios: el del "genio" artístico de Fidias, Lisipo y Praxíteles"36, el de la alabanza a Grecia como "Edad de Oro" de la Humanidad (Iles, séjour des Dieux! Hellas, mère sacrée, v. 41) y el de la lamentación del poeta por no haber nacido en ella (Oh! Que ne suis-je né dans le saint Archipel / Aux siècles glorieux... vv. 4243). En los poemas de su etapa fourierista, la Grecia soñada por Leconte de Lisle resplandece como un "archipiélago encantado" en el que aún brilla el fuego de Prometeo, la vibración de la lira acompaña los dedos del artista y la estatua cobra vida en las manos del escultor 37

$\mathrm{O}$ vous qui saisissez la vivante harmonie

De la forme parfaite alliée au génie, Apôtre épris d'amour pour l'antique beauté

Venez! - Allons revoir l'archipel enchanté,

\section{Le paradis païen, la contrée immortelle}

Où rayonne Aphrodite au coeur de Praxitèle;

Où les dieux helléniens, Paros immaculé

De qui le ciel attique a seul été foulé,

Jaillissent, lumineux, sous la main qui les crée,

Dans leur nudité chaste et leur pose sacrée...38

\footnotetext{
34 Quinet, E., «Du génie de l'art», en Revue des deux mondes, Paris, T. XX (1839), p. 140.

35 "Así como las profundidades del mar permanecen siempre en calma por muy furiosa que la superficie pueda estar, también la expresión en las figuras de los griegos revela, en el seno de todas las pasiones un alma grande y equilibrada". En Wincklemann, J. J., Reflexiones sobre la imitación del arte griego en la pintura y la escultura, Barcelona, Nexos, 1987, p. 36.

36 Tópico creado por el Renacimiento italiano.

37 Ducros 1981, op. cit. (nota 16), p. 37.

38 Leconte de Lisle, Ch.-M., «Hélène», Paris, La Phalange, II (1845), p. 179.
} 
A pesar de su entusiasmo poético, Leconte del Lisle fue consciente de que su tiempo era otro, un tiempo de malestar e inquietud, de búsqueda incierta en el que la pérdida de esa juventud edénica debía ser asumida 39 . En este sentido, fue consciente también (como otros poetas coetáneos suyos) de la imposibilidad de una vuelta a la Antigüedad como la planteada por Hölderlin, por ejemplo, con quien compartió, sin embargo, la obsesión por la recreación formal de modelos del pasado. A pesar de ello, sí asumió la visión metafórica de Grecia defendida por Hegel y otros idealistas alemanes que pensaban en ella como la "tierra de la armonía y de la juventud del espíritu" (entendiendo por "juventud" esa frescura concreta en la que espontáneamente el espíritu se encarna y la sensibilidad se espiritualiza ${ }^{40}$ ). Por este motivo, la aproximación de Leconte de Lisle a la Antigüedad nunca fue exclusivamente literaria ni artística sino que se caracterizó por un interés global por la cultura griega. Porque para comprender el "genio griego" y ser capaz de generar un esplendor de espíritu similar, y éste sí que es uno de los postulados del idealismo alemán, era necesario beber de la totalidad de sus fuentes.

Leconte de Lisle hace tres peticiones a la diosa en las estrofas finales del poema: una en nombre de la Humanidad y del Universo mismo: "Sois de l'humanité la divine maîtresse et berce sur ton sein les mondes et les cieux" (vv. 60), en la que deja entrever su filiación furierista ${ }^{41}$; $y$ dos personales en las que la voz poética nos hace partícipes de sus temores y sus anhelos como creador
Allume dans mon sein la sublime étincelle,
N'enferme point ma gloire au tombeau soucieux ${ }^{42}$
Et fait que ma pensé en rythmes d'or ruiselle,
Comme un divin métal au moule harmonieux ${ }^{43}$

\footnotetext{
39 "Nous sommes une génération savante; la vie instinctive, spontanée, aveuglément de la jeunesse, s'est retirée de nous; tel est le fait irreparable." Leconte de Lisle 1994, op. cit (nota 15), p. 310

40 Mayos, G., Marxa i sentit especulatius de la Historia. Comentari a Hegel, Barcelona, Ed. PPU, 1993, p. 98.

41 "Dans les années 1840, la théorie de l'harmonie des sphères avait été reprise et développée par Fourier, en particulier dans les manuscrits publiés à titre posthume dans La Phalange entre 1845 et 1948." Corbier, Ch., "Le Beau idéal incarné: Leconte de Lisle et la musique grecque", Romantisme, $150(2010-4)$.

42 En los versos iniciales de su Oda III.30, Horacio (el único poeta latino al que Leconte de Lisle tradujo y el que mereció más atención en sus recreaciones) dice: "He levantado un monumento más perenne que el bronce y más alto que la regia construcción de las pirámides, que ni la lluvia voraz, ni el Aquilón desenfrenado podrán derruir, ni la innumerable sucesión de años y la fuga de las generaciones. No moriré por completo..." Horacio, Epodos.Odas, Madrid, Alianza Editorial, 2005 (trad. Vicente Cristóbal).

43 Hippolyte Taine, en su estudio sobre la filosofía del arte en Grecia de 1869, consideró el ritmo como "le moule primitif et persistant d'où le monde grec est sorti." Philosophie de l'art, Fayard, 1985, p. 333.
} 
Déesse! Fais surtout qu'embrasé de ta flamme

À ton culte éternel je consacre mes jours;

Que je n'étouffe pas sur les autels de l'âme

La forme, chère aux dieux, fleur de leurs amours!

En su apasionada petición a Venus la voz poética de Leconte de Lisle establece un vínculo complejo entre poesía, representación plástica y música, una interrelación en la que el ritmo 44 juega un rol determinante en la inmortalidad de la obra poética. En La Mélodie incarnée, un cuento publicado un mes antes en La Démocratie pacifique, Leconte de Lisle narra la historia de un violinista alemán que, después de un revelador paseo por el campo, compone una melodía perfecta que se transforma en una hermosa joven cuya descripción coincide sospechosamente con la Venus de Milo

Pardieu! à quoi voudriez-vous qu'elle ressemblât, si ce n'est à la grâce par excellence, à ce que Dieu a formé de plus parfait, au corps sublime et nu d'une femme jeune et belle? - Elle était là, devant Samuel, lumineuse dans l'ombre de la chambre, et légèrement inclinée sur sa hanche; mais si harmonieuse de lignes et de contours, si pure de coupe et si admirablement posée, que le pauvre jeune homme comprit bien qu'il perdrait la tête s'il devait cesser de la voir45

La imagen de esa joven, que es estatua, melodía y alma del violín a la vez, aparece en el instante en el que el músico (alter ego del poeta) percibe claramente lo que invisiblemente las relaciona, es decir, cuando logra comprender la Belleza más allá de sus múltiples manifestaciones. Entonces la armonía celeste resuena por fin en su corazón y en su mente, sus dudas desaparecen y, gracias a su maravillosa melodía que es puro amor a la Belleza, triunfa sobre la muerte.

\section{Conclusión}

Después de este breve análisis, resulta evidente que Leconte de Lisle se encontró con una recodificación "acabada" que él adaptó sin problemas a su ideario poético. Esa es la causa, en mi opinión, de que en ningún momento mencione el estado fragmentario de la estatua, reconvertida ya en símbolo de la Belleza.

Aparentemente, el poema de Leconte de Lisle aporta muy pocas novedades respecto a otros textos de su época de temática similar. El léxico escogido, sus metáforas e imágenes poéticas, su descripción de la estatua o, incluso, su evocación de

44 La expresión rythmes d'or podría ser una alusión al "numero áureo" de los pitagóricos.

45 Leconte de Lisle, Ch.-M., Contes en prose (Impressions de jeunesse), Paris, Société Normande du livre illustré, 1910, p. 67. 
Grecia, todo nos suena conocido. Sin embargo, analizando detenidamente el poema y contrastándolo con otros textos suyos, nos encontramos con que, además de la claridad de la forma y de la musicalidad que le caracteriza, Leconte de Lisle sí ha añadido un elemento realmente novedoso a esa recodificación. Gracias a la asociación final de la música con la poesía y la escultura, Leconte de Lisle introduce un elemento dinámico en la inmovilidad "platónica" de la estatua que le permite relacionar sin problemas la eternidad cósmica de la diosa con la fluidez incandescente de la experiencia creadora. 